\title{
Lymphoid Leukemia in Remission
}

National Cancer Institute

\section{Source}

National Cancer Institute. Lymphoid Leukemia in Remission. NCI Thesaurus. Code C4901.

Lymphoid leukemia not growing, responding to treatment. 